\title{
Comparison of Glucose \& Lipid Profiles in Oxidative Stress Contain Diabetic Patients
}

\author{
K. Rajan, M. Naresh kumar. \\ (Lecturer of Biochemistry, RVS dental college, Coimbatore, India), Mathavan, Umabathi
}

\begin{abstract}
Oxidative stress which influences the glucose profile \& lipid profile in diabetic patients. Patient with diabetes may also prominent to the symptoms that are repercussion upon the altered glucose \& lipid profile levels. The study shows that, comparision of glucose \& lipid profiles variations in oxidative stress contain diabetic patients.

Materials \& Methods- The study was conducted over a period of six months. In this study 30 subjects are diabetic \& 20 subjects are control. Diabetic patients are selected. Both males and females were included. Blood sample were collected for estimation of Fbs, PPbs, lipid profile.

Results- In diabetic patients the plasma or serum levels glucose profile \& lipid profile $(p<0.001)$ except VLDL $(p<0.01)$. Here VLDL is significant but other all profiles are highly significant. Oxidative profile MDA $(p<0.001)$ \& Glutathione $(p<0.01)$. Glutathione is significant but MDA is highly significant.

Conclusion- Glucose profile \& lipid profile in oxidative stressed diabetic patients status is observed. Fbs \& PPbs levels are high; lipid profile levels are high except HDL. Oxidative stress influences the diabetic glucose profile \& lipid profile.
\end{abstract}

Key words: Fbs, PPbs, lipid profiles (total cholesterol, $H D L, L D L, V L D L, T G L$ ).

\section{INTRODUCTION}

Diabetes mellitus is classified into 2 major types, 1.Insulin dependent diabetes mellitus, and 2.Non-Insulin dependent diabetes mellitus.

1. Insulin dependent diabetes mellitus:

In diabetic patients the circulating insulin level is deficient.

Type-I diabetes is seen in 12-15 years aged peoples.

About $5 \%$ of total diabetic patients are type-I.

2. Non-Insulin dependent diabetes mellitus:

Most of the patients belongs this type.

NIDDM occurs in adult (Usually occurs above 35 years of age).

Here circulating insulin is normal or mildly elevated or slightly decreased.

Depending on the stage of this disease this type is further classified as:

a. Obese

b. Non-obese

c. Maturity onset diabetes of young (MODY).

\section{MATERIALS AND METHODS}

The study was conducted over a period of 6 months in Narayana Medical College \& Hospital. In this study we have included 30 diagnosed 30 diabetic \& 20 healthy people.

Plasma Glucose is estimated by GOD-POD method.

Serum cholesterol is estimated by CHOD-POD/ Phosphotungstate method.

Plasma sample is estimated in reduced Glutathione in RBC.

Serum TGL is estimated by GPO-POD method with TBHA as chromogen.

Plasma contain lipid peroxides are estimated (MDA \& Glutathione).

\section{RESULTS}

The values obtained on analyzing specimens collected from patients and control groups are tabulated.

The mean values and standard deviation also have been calculated for comparative study of patients and controls.

The values of patients and controls groups are also graphically represented for comparison at a glance.

TABLE- 1 
Shows the mean \pm standard deviation of FBS, PPBS in 30 diabetic subjects and 20 controls.

FIGURE -1

Shows the FBS, PPBS mean graphical comparison of Diabetes mellitus patients and controls.

TABLE 2: controls.

Shows the status of mean and standard deviation of lipid profile, in 30 diabetic subjects and 20

FIGURE- 2

Shows the mean graph comparison of lipid profile in Diabetes mellitus patients and controls.

TABLE 3:

Shows the mean \pm standard deviation of Malondialdehyde in 30 diabetic subjects and 20 controls.

FIGURE-3

Shows the mean graph comparison of Malondialdehyde in Diabetes

Mellitus patients and controls.

\begin{tabular}{|c|c|c|c|c|c|c|}
\hline \multirow[t]{2}{*}{ Sl. No } & \multirow{2}{*}{$\begin{array}{l}\text { Parameter } \\
\text { (mg/dl) }\end{array}$} & \multicolumn{2}{|c|}{ CASES } & \multicolumn{2}{|c|}{ CONTROLS } & \multirow[t]{2}{*}{ p VALUE } \\
\hline & & Mean & S.D. & Mean & S.D. & \\
\hline 1 & FBS & 154 & 11 & 89 & 6 & $\begin{array}{l}<0.001 \\
\text { HS }\end{array}$ \\
\hline 2 & PPBS & 237 & 14 & 123 & 11 & $\begin{array}{l}<0.001 \\
\text { HS }\end{array}$ \\
\hline
\end{tabular}

TABLE-4:

Shows the mean \pm standard deviation of reduced glutathione in 30 diabetic subjects and 20 controls.

FIGURE-4

Shows the mean graph comparison of reduced glutathione in Diabetes mellitus patients and controls.

TABLE-1

Blood sugar levels in patients and controls

HS = highly significant

FIGURE-1

Comparison of mean graph for diabetes patients and controls

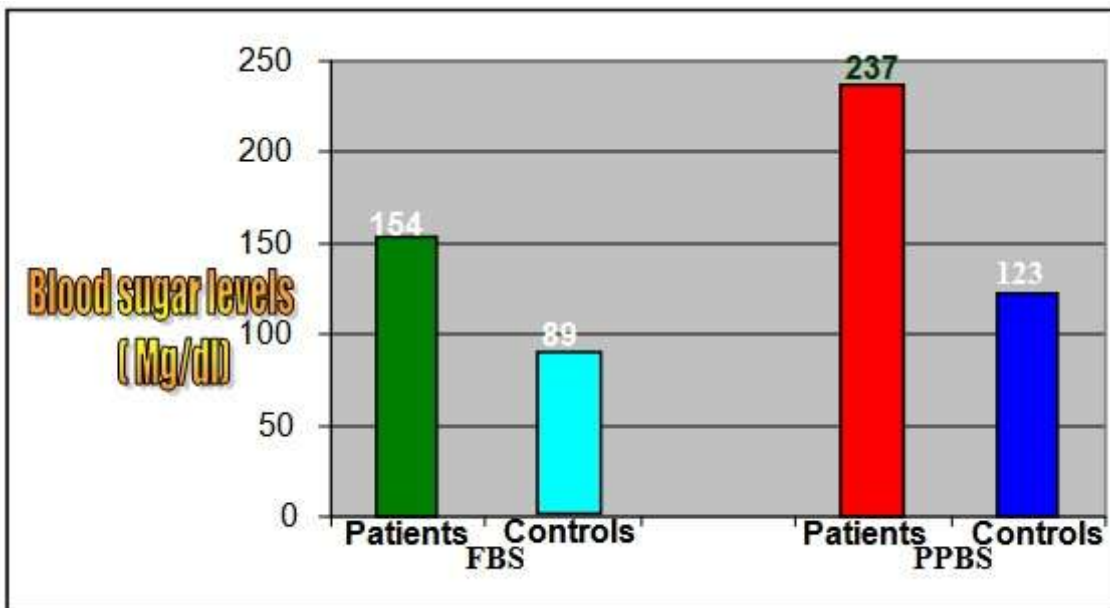

TABLE-2 
Lipid profile status in patients and controls

\begin{tabular}{|c|c|c|c|c|c|c|}
\hline \multirow{2}{*}{ S1. No } & $\begin{array}{c}\text { Parameter } \\
(\mathrm{mg} / \mathrm{dl})\end{array}$ & \multicolumn{2}{|c|}{ CASES } & \multicolumn{2}{c|}{ CONTROLS } & \multirow{2}{*}{ p VALUE } \\
\cline { 3 - 6 } & Mean & S.D. & Mean & S.D. & \\
\hline 1 & TOTAL CHOLESTEROL & 232 & 15 & 204 & 16 & $\begin{array}{c}<0.001 \\
\text { HS }\end{array}$ \\
\hline 2 & HDL & 47 & 9 & 64 & 8 & $\begin{array}{c}<0.001 \\
\text { HS }\end{array}$ \\
\hline 3 & LDL & 143 & 11 & 102 & 9 & $\begin{array}{c}<0.001 \\
\text { HS }\end{array}$ \\
\hline 4 & VLDL & 42 & 8 & 38 & 7 & $\begin{array}{c}<0.1 \\
\text { S }\end{array}$ \\
\hline 5 & TRIGLYCERIDES & 216 & 13 & 189 & 11 & $\begin{array}{c}<0.001 \\
\text { HS }\end{array}$ \\
\hline
\end{tabular}

HS = highly significant $\quad$ S = significance

FIGURE-2

Comparison of mean graph for Lipid profile in patients and controls

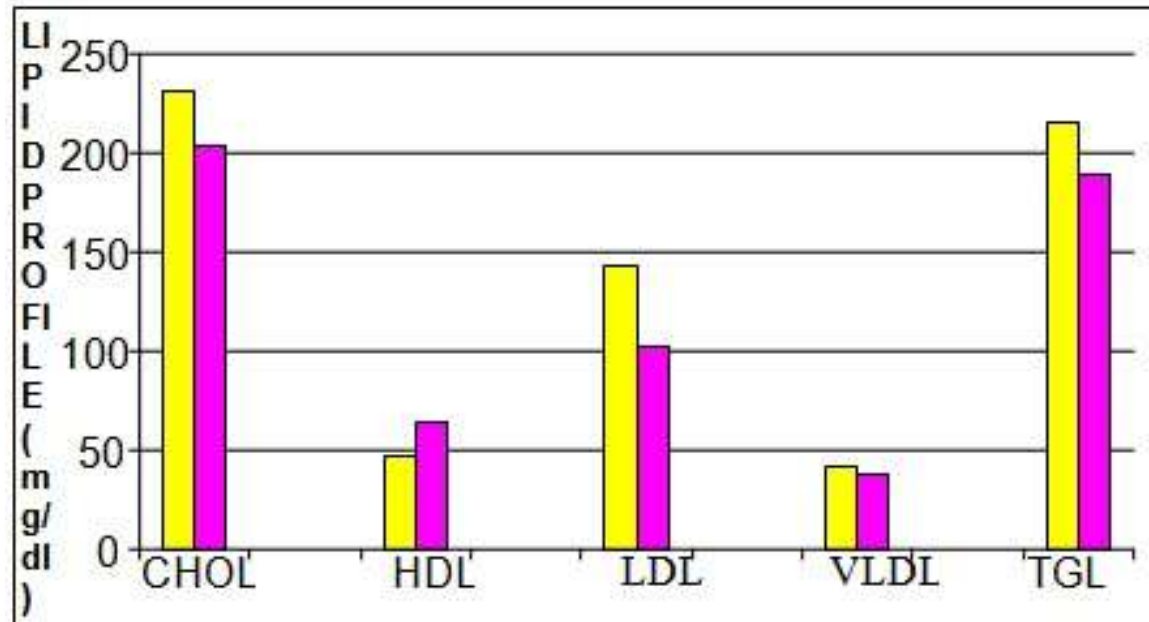

\section{$\square \quad$ PATIENTS $\square$ CONTROLS}

Lipid profile values $(\mathbf{m g} / \mathbf{d l})$

TABLE-3

Lipid peroxidation (MDA) between patients and controls

HS = highly significant

\begin{tabular}{|c|c|c|c|c|c|c|}
\hline \multirow{2}{*}{ Sl. No } & Parameter & \multicolumn{2}{|c|}{ CASES } & \multicolumn{2}{c|}{ CONTROLS } & \multirow{2}{*}{ p VALUE } \\
\cline { 3 - 6 } & & Mean & S.D. & Mean & S.D. & \\
\hline 1 & MDA & 4.9 & 0.9 & 1.7 & 0.4 & $\begin{array}{c}<0.001 \\
\text { HS }\end{array}$ \\
\hline
\end{tabular}

FIGURE-3 
Comparison of mean graph for Malondialdehyde in patients and controls

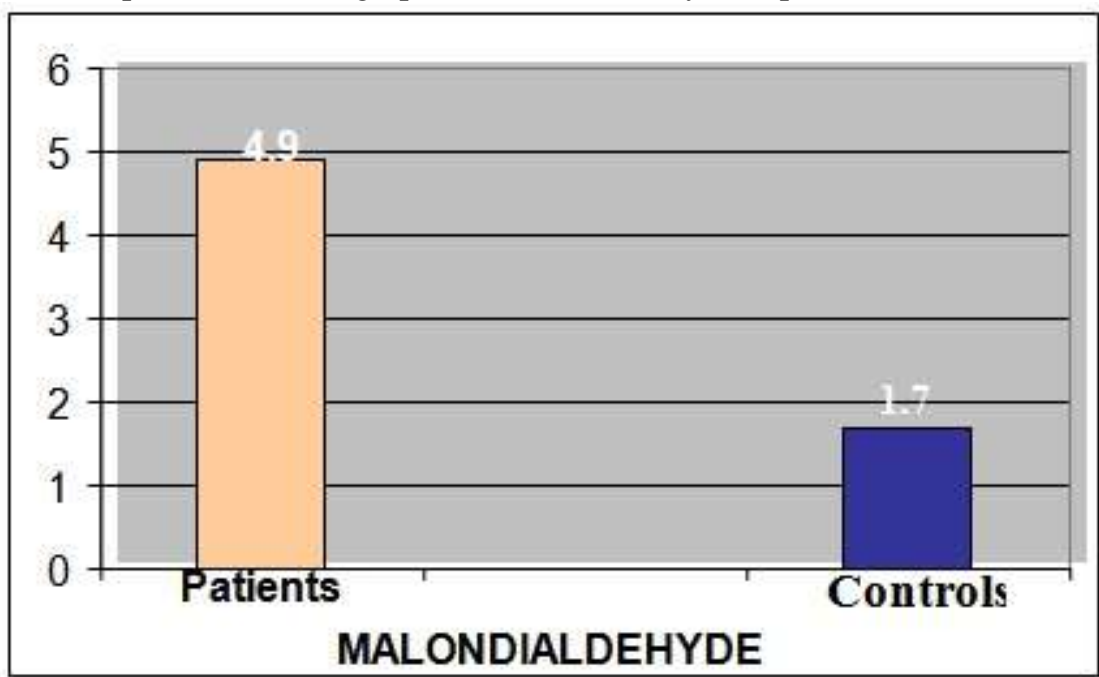

$\square$ PATIENTS $\square$ CONTROL

\section{Malondialdehyde (umol/L)}

TABLE-4

Antioxidant (GSH) between patients and controls

$\mathrm{S}=$ significance

\begin{tabular}{|c|c|c|c|c|c|c|}
\hline \multirow{2}{*}{ S.No } & Parameter & \multicolumn{2}{|c|}{ CASES } & \multicolumn{2}{c|}{ CONTROLS } & \multirow{2}{*}{ p VALUE } \\
\cline { 3 - 6 } & Mean & S.D. & Mean & S.D. & \\
\hline 1 & $\begin{array}{c}\text { REDUCED } \\
\text { GLUTATHIONE } \\
(\mu \mathrm{mol} / \mathrm{gHb} \%)\end{array}$ & $\mathbf{3 . 6}$ & $\mathbf{0 . 6}$ & $\mathbf{4 . 9}$ & $\mathbf{0 . 5}$ & $<\mathbf{0 . 0 1}$ \\
& & & & & S \\
\hline
\end{tabular}

FIGURE-4

Comparison of mean graph for reduced glutathione in patients and controls.

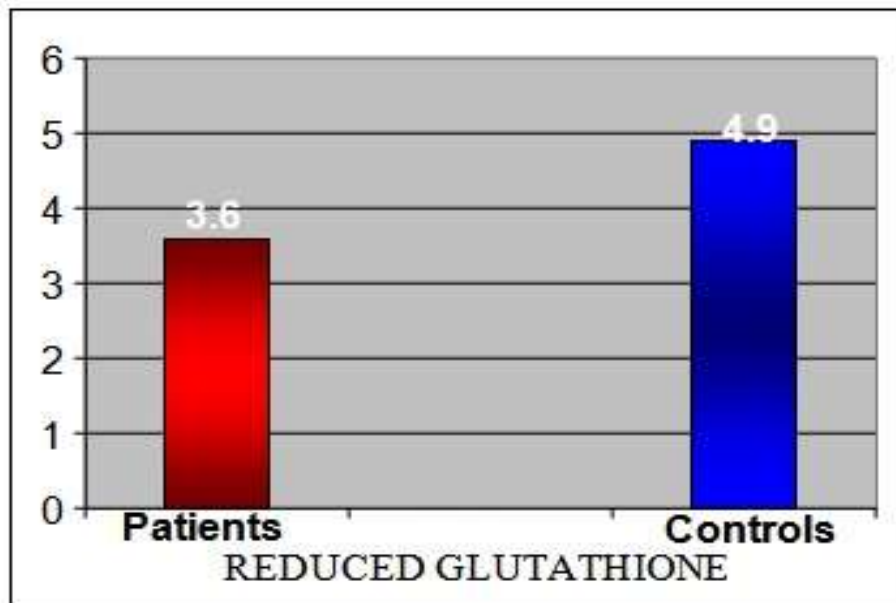

PATIENTS

CONTROLS

\section{Reduced glutathione}

$\mu \mathrm{mol} / \mathrm{gHb} \%$ 


\section{DISCUSSION}

The present studies were undertaken to assess the status of oxidative stress in diabetes mellitus. As diabetes advances, especially in ill treated patients, it leads to microvascular damage causing various complications. In the present study the patients were suffering from DM for the past 5 to 10 years.

Reduced glutathione concentration was measured as markers of antioxidant. Glutathione is an important antioxidant and its values were reported to be low in diabetes patients with oxidative stress. Reduced glutathione is a tripeptide with free - $\mathrm{SH}$ group and hence it is an antioxidant. In the present study glutathione values were substantially reduced and coincide with earlier reports $(3.6 \pm 0.6)$.

Thus the present study supports the following:

1. All the patients of substantial hyperglycemia are subjected to oxidative stress and various biochemical parameters indicative of oxidative stress are significant.

2. Glutathione levels in RBC were substantially reduced and hence it can be considered as a measure of oxidant damage of vascular endothelium.

3. The extent of oxidant damage can also be assessed MDA concentration in serum which is shown to be elevated as pro-oxidant molecule in oxidative stress.

4. The effect of oxidative stress is damage on vascular endothelium which effects kidney and causes renal failure and heart causes coronary heart disease and on eyes leads to retinopathy.

It is advisable to have screening for parameters like glutathione, Malondialdehyde in all diabetics along with plasma glucose, so that can be effectively monitoring the diabetes.

\section{CONCLUSION}

This study shows the association of increased free radicals and decreased antioxidant status with response to increase in Fbs, PPbs, Lipid profiles except HDL; MDA \& Glutathione are slightly increased.

This study concludes the oxidative stress influence the increase level of glucose profile $\&$ lipid profiles except HDL.

\section{REFERECES}

\section{REFERENCE FOR ESTIMATION OF GLUCOSE}

[1] Estimation of glucose by the method of GOD-POD. [Trinder, P. (1969, Annals. Clin. Bio Chem, 6, 24].

\section{REFERENCE FOR ESTIAMTION OF CHOLESTEROL}

[2] Schettler, G. and Nussel, E., Arb. Med, soz. Med. 10, 25 (1975).

[3] Richmond, W., Clin. Chem. Clin. Biochem. 12, 403 (1973).

[4] Rochalu, p. et al, J. Clin. Chem. Clin. Biochem. 12, 403 (1974).

\section{REFERENCE FOR ESTIMATION REDUCED GLUTATHIONE}

[5] Estimation of erythrocyte glutathione. [Teitz, Biochemical aspects of Haematology, 1652-1653]. 